\title{
O exame colpocitológico sob a ótica da mulher que o vivencia*
}

\author{
THE SMEAR TEST UNDER THE POINT OF VIEW OF THE WOMAN WHO HAS \\ EXPERIENCED IT IN HER LIFE
}

\section{EL EXAMEN COLPOCITOLÓGICO DESDE LA ÓPTICA DE LA MUJER QUE LO VIVENCIA}

\section{Aline Fernandes de Paula ${ }^{1}$, Anézia Moreira Faria Madeira ${ }^{2}$}

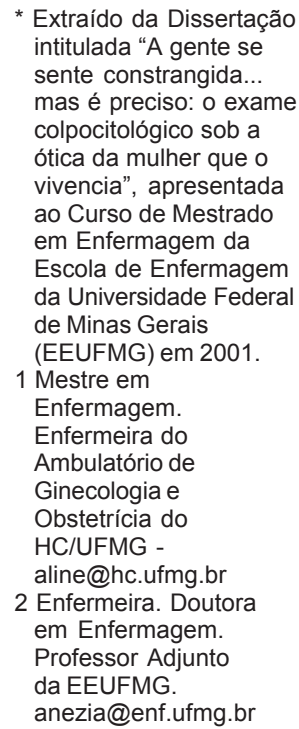

Rev Esc Enferm USP
2003; 37(3): 88-96.

Rev Esc Enferm USP
2003; 37(3): 88-96.

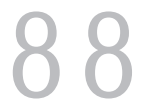

\begin{abstract}
RESUMO
Esta pesquisa é fruto de minha experiencia com mulheres no Programa de Prevenção do Câncer Cérvico-uterino do Ambulatório de Ginecologia e Obstetrícia do Hospital das Clínicas da UFMG. Busquei compreender o que significa para as mulheres se submeterem ao exame colpocitológico. Para tal, utilizei-me da pesquisa qualitativa, numa abordagem fenomenológica. Para coletar os dados foi utilizada uma entrevista aberta. A análise dos discursos das onze mulheres entrevistadas possibilitou-me construir três categorias analiticas: A-Prevenindo o câncer cérvico-uterino: a mulher como ser-consciente-no-mundo; $B$-Enfrentando o exame colpocitológico: manifestações do ex-istir; $C$-Interagindo com o profissional de saúde durante o exame: as interfaces da assistência.
\end{abstract}

\author{
PALAVRAS-CHAVE \\ Enfermagem. Saúde da \\ mulher. Colposcopia. \\ Relações enfermeira/paciente.
}

\author{
ABSTRACT \\ This research is the result \\ of my experience with women \\ in cervical cancer prevention at \\ the Gynecology and Obstetrics \\ National Health Clinic of \\ the Federal University of \\ Minas Gerais. I tried to \\ understand what it means to \\ women who are submitted to a \\ smear test. To achieve this, I \\ have used a qualitative \\ research, in a \\ phenomenological approach. \\ I gathered the data from \\ interviews about the main \\ subject. The analysis of those \\ eleven interviews have helped \\ me to build three analytical \\ categories that are the located \\ structure of the phenomenon, as \\ follows: A-The preventive \\ cervical cancer examination: \\ a woman as a human being \\ conscious of the world; $B$ - \\ Facing the smear test: \\ manifestation of the existence; \\ $C$ - Working with the health \\ professional during the \\ examination: as interfaces of \\ the attendance.
}

\section{KEYWORDS}

Nursing. Women's health. Nurse-patient relations. Colposcopy

\section{RESUMEN}

Esta investigación es fruto de mi experiencia con mujeres en el Programa de Prevención de Cáncer Cérvico-uterino del Consultorio externo de Ginecología y Obstetricia del Hospital de Clinicas de la UFMG. Quería comprender lo que significa para las mujeres someterse al examen colpocitológico. Para tal fin, utilicé el método de investigación cualitativo con abordaje fenomenológico. Para la recolección de datos fue utilizada la entrevista con preguntas abiertas. El análisis de los discursos de once mujeres entrevistadas me permitió construir tres categorías analíticas: APreviniendo el cáncer cérvicouterino: la mujer como ser conciente del mundo; $B$ Enfrentando el examen colpocitológico: manifestaciones del existir; $C$ Interactuando con el profesional de salud durante el examen: las interfases de la asistencia.

\section{PALABRAS-CLAVE}

Enfermería. Salud de las mujeres. Colposcopia. Relaciones enfermera/paciente. 


\section{INTRODUÇÃO}

O câncer cérvico-uterino é uma das causas de mortalidade mais freqüente na população feminina da América Latina e do Caribe e sua incidência se encontra entre as mais altas do mundo. No Brasil, dentre as neoplasias, a cervical é uma das maiores causas de óbito entre as mulheres, juntamente com o câncer de pele, mama e pulmão ${ }^{(1-2)}$. As repercussões do câncer de colo uterino são imensas e incluem implicações para o doente, família e sociedade em geral.

Contraditoriamente aos números alarmantes que caracterizam o quadro mundial e nacional citado, este é o único câncer para o qual se dispõe de tecnologia para prevenção, detecção precoce e tratamento. Entretanto, ao contrário do que vem acontecendo em países mais desenvolvidos, não são evidenciadas reduções significativas nos índices de morbimortalidade das mulheres brasileiras pela doença, embora esforços tenham sido despendidos nesse sentido desde a década de $40^{(3)}$. Segundo Silveira e Pessini ${ }^{(4)}$, em regiões pobres e subdesenvolvidas do país o câncer do colo uterino é o tumor mais freqüente, chegando a quase $50 \%$ das lesões malignas na mulher.

O controle do câncer cérvico-uterino obedece a estratégia de prevenção secundária, baseada na citologia cervical. Este método é o mais difundido mundialmente para rastreamento da neoplasia intra-epitelial cervical (NIC). Ele é internacionalmente apontado como o instrumento mais adequado, sensível, de baixo custo, além de ser conhecido e aceito pelas mulheres para o seu rastreamento. $\mathrm{Na}$ maioria dos serviços especializados, o rastreamento da doença por essa técnica tem sido superior a $80 \%{ }^{(5)}$.

No entanto, os programas de prevenção da doença, apesar do discurso de integralidade, contemplam de forma enfática o cuidado com o corpo físico/biológico, permanecendo veladas as subjetividades das mulheres e dos profissionais que as atendem. Desta forma, as mulheres acabam sendo responsabilizadas, direta ou indiretamente, pelo eventual infortúnio do aparecimento do câncer cérvico-uterino, sob a alegação de que a ignorância, a desinformação e a relutância em realizar o exame preventivo as conduziram a este trágico desfecho, pois os programas de prevenção da doença existem e estão disponíveis à toda população.
Foi sob essa perspectiva - de buscar os significados do exame colpocitológico para a mulher que o vivencia - que as minhas inquietações foram paulatinamente surgindo.

Durante $\mathrm{o}$ atendimento às mulheres, no Serviço de Prevenção do Câncer Cérvico-uterino do Hospital das Clínicas da UFMG (HC/UFMG) percebia que muitas mulheres, num primeiro momento, não relatavam o motivo principal que as tinham levado àquele atendimento. Nesses momentos, eu me sentia incomodada por atender a mulher sem saber o que ela realmente queria ou precisava naquela consulta.

Observei também a relutância de muitas mulheres em realizar o exame colpocitológico. Era visível em suas fisionomias o constrangimento e a contrariedade por estarem se submetendo ao procedimento.

A impotência, a perda do domínio sobre o próprio corpo, o temor da descoberta de alguma "anormalidade", tudo isso parecia influenciar nesse comportamento.

Essas reflexões tornaram-se cada vez mais presentes no meu cotidiano com essas mulheres e suscitaram em mim diversas inquietações.

Viver a experiência e poder descrevê-la é falar de uma intencionalidade, uma faceta vivenciada em um tempo e um espaço existencial. Portanto, as mulheres, somente elas, poderiam descrever com pormenores o que isso significou para elas, esse momento íntimo, particular com a enfermeira, no exame colpocitológico, respondendo assim às minhas inquietações.

A compreensão dos significados emergidos das falas das mulheres submetidas ao exame colpocitológico poderá direcionar um novo caminho no assistir/cuidar dessa clientela pela equipe de saúde, e, em particular, pela equipe de enfermagem, contribuindo para a transformação de uma prática assistencial e melhor compreensão do mundo-vida das clientes, proporcionando, em última instância, um atendimento mais adequado às necessidades da população feminina, um cuidar autêntico, que certamente ocasionará a diminuição da morbimortalidade pelo câncer de colo uterino.

Assim pretendi, sob a luz da fenomenologia, compreender o significado que as mulheres atribuem ao exame colpocitológico.
O exame colpocitológico sob a ótica da mulher que o vivencia 


\section{TRAJETÓRIA METODOLÓGICA E REFERENCIAL TEÓRICO}

Como enfermeira assistencial e pesquisadora, entendo que as vivências das mulheres durante o exame colpocitológico merecem ser melhor compreendidas, uma vez que se trata de uma experiência vivenciada por cada uma delas em seu mundo-vida. Assim, elegi a fenomenologia como trajetória de pesquisa, uma vez que ela se presta a descrever, explicitar e compreender a essência do vivido dos sujeitos. Para fundamentar a análise compreensiva/interpretativa das categorias analíticas, utilizei, além dos autores que trabalham a temática estudada, a fenomenologia existencial à luz de Maurice Merleau-Ponty.

Optei por desenvolver o trabalho no Ambulatório de Ginecologia e Obstetrícia do HC/ UFMG, por ser ali o lugar onde surgiram as minhas inquietações e por já estar familiarizada com o ambiente, com os funcionários, e principalmente, com a clientela.

Os sujeitos foram mulheres atendidas no Ambulatório que haviam se submetido ao exame colpocitológico. Para obtenção dos dados utilizei uma entrevista aberta, norteada pela questão: "Conta para mim o que foi para você fazer o exame de prevenção". Antes, porém, do processo de coleta de dados, busquei atender as exigências do Conselho Nacional de Saúde e submeti o projeto ao Comitê de Ética da Universidade Federal de Minas Gerais, atendendo assim, à Resolução de $n^{\circ}$ 196/96, que trata de pesquisas envolvendo seres humanos ${ }^{(6)}$. Após apresentação sucinta da pesquisa aos sujeitos participantes do estudo, convidava-os para participarem. Caso aceitassem, informava-lhes sobre a necessidade de ter o seu consentimento por escrito.

Como recurso metodológico utilizei o gravador, que me permitiu registrar os depoimentos na íntegra. As entrevistas foram transcritas em sua totalidade; interrompi as mesmas ao perceber que os conteúdos estavam se tornando repetitivos, evidenciando o invariante, o comum nos relatos dos sujeitos. Encerrei esta etapa, totalizando 11 (onze) entrevistas, por compreender que já havia alcançado a saturação dos discursos.

De posse dos relatos prossegui realizando a análise compreensiva dos significados emergidos dos discursos. Para isso fundamentei-me nos passos propostos por Martins e Bicudo $^{(7)}$, também denominado análise ideográfica: Primeiramente fiz uma leitura geral de cada discurso apreendendo o sentido do todo; logo em seguida identifiquei as unidades de significado presentes nos depoimentos; feito isto, agrupei-as conforme semelhanças e diferenças e cheguei a três grandes categorias de análise que se configuraram na estrutura do fenômeno (essência), ou seja, a verdade para os sujeitos participantes deste estudo. São elas: A- Prevenindo o câncer cérvico-uterino: a mulher como ser-consciente-no-mundo; B- Enfrentando o exame colpocitológico: manifestações do ex-istir; C- Interagindo com o profissional de saúde durante o exame: as interfaces da assistência.

\section{A CONSTRUÇÃO DOS RESULTADOS}

\section{Prevenindo o câncer cérvico-uterino: a mulher como ser-consciente-no-mundo}

Esta categoria explicita as bases de um relacionamento significativo da mulher consigo mesma, com o outro e com o mundo. A mulher estabelece uma relação dialética de observação e cuidado consigo mesma e com o próprio corpo, ao mesmo tempo em que os depoimentos expressam a adesão à atividade de prevenir o câncer cérvico-uterino, revelam a situação conflituosa em que a mulher vive, da qual emergem sentimentos de medo, vergonha e insegurança.

Emerge, também, a consciência dos sujeitos da importância da con-vivência e da interação com o outro, incentivando outras mulheres a se reconhecerem como ser, na prevenção do câncer cérvico-uterino.

As mulheres têm consciência dos riscos que correm de adoecer caso não façam o exame preventivo. Essa consciência aparece de forma explícita ou velada na maioria das falas das mulheres, em maior ou menor intensidade, de acordo com o que cada uma delas traz registrado em sua existência:

Pra mim é super natural, é uma coisa que eu sei que faz bem pra saúde, que tem que ser feita.

Nos discursos dos sujeitos fica explícita a importância que as mulheres atribuem ao cuidar-se. Elas utilizam-se do exame colpocitológico para evitar o câncer cérvicouterino e sabem que este exame é um meio 
eficaz na prevenção e combate da enfermidade, reconhecem seus benefícios.

Apesar das mulheres terem consciência da importância de se cuidarem por meio do exame colpocitológico, a experiência de submeter-se a ele não lhes é agradável. Ser um exame rotineiro não o torna menos desagradável ou constrangedor, como nos mostram o depoimento:

... eu mesma sei que tenho que ter dó de mim e cuidar da minha saúde [...] eu sei que você tá fazendo pro meu bem, mas eu tenho que passar por aquilo ali, se eu quero a minha felicidade, ter saúde e tudo, né? [...] chato é, mas fazer o que? [...] Não é um bicho de sete cabeças e é pro meu bem.

Nessa relação entre o "necessitar" e o "não querer" a responsabilidade sobre o próprio corpo, a própria vida e o medo da morte suplantam os sentimentos desfavoráveis, num movimento que esboça conscientização de uma existência plena.

Através desta perspectiva, podemos apreender o medo e a ansiedade explicitados mediante a espera pelo resultado, bem como, o alívio que as mulheres relatam sentir após recebê-lo:

... pelo menos eu vou saber se tá tudo bem, se tá tudo em paz, se tá tudo direito comigo, não sei [...] se Deus quiser vai dar tudo certo.[...] Só de saber que eu tô fazendo um exame ali que vou ter o resultado, saber realmente se tá tudo beleza, pra mim é muito importante.[...] eu também fico pensando: será que o exame vai dar tudo ok? Será que tá tudo certo? Se eu pudesse, já pegaria o resultado ali na hora mesmo, pra tirar as dúvidas.

Dessa forma, os relatos das mulheres levam-me a inferir que o cuidado com o corpo provém principalmente do medo da doença, da dor e da morte, e esse medo é um dos principais motivos que as leva ao serviço de saúde em busca da prevenção do câncer cérvicouterino. Porém, não há como negar que está presente a preocupação em cuidar de um corpo feminino, não apenas físico, social, cultural e espiritual, mas existente, perceptivo, que estabelece com o mundo e com o outro uma relação de autenticidade.

E é uma maneira também da gente estar se conscientizando, em muito, do que é ser mulher, qual o papel da gente, não só social como também consciência física.
Esta mulher fala da percepção do corpo como um ex-istir pleno, forma de estar-nomundo. Fala da necessidade de estar consciente, interagindo, sobretudo, consigo mesma. Ela explicita sua concepção de cidadania, encarando o corpo como lugar primeiro da existência humana.

Assim, o cuidar do corpo assume dimensões que transcendem o desejo de submeterse ou não ao exame colpocitológico, pela necessidade real e imaginária da mulher em afastar o fantasma da doença.

É possível perceber nos depoimentos que as mulheres mostram-se empenhadas em cuidar não só de si, mas também, das pessoas de seu convívio. Cuidar, para essas mulheres, é mais do que um ato: é uma atitude, é compartilhar:

... e passei isso também pras minhas fi-
Ihas e pras outras pessoas também, pra
não ter aquele medo de fazer [...] eu pro-
curo passar isso pras outras pessoas
[...] sempre que eu tô conversando com
alguém também eu falo: [...] faz, porque
saúde a gente não pode deixar de lado,
tem que tá olhando...

As mulheres desenvolvem, enquanto irmãs, mães e mulheres, ações que visam conscientizar outros sujeitos, com a finalidade de evitar que a doença se instale entre as mulheres de sua convivência. Para tal, observo que elas conferem grande credibilidade ao exame colpocitológico como meio para prevenir o câncer cérvico-uterino, procurando transmitir esse sentimento de confiança adiante. Observo, ainda, que é apostando nos benefícios inegáveis do procedimento que elas recomendam, de forma unânime, que todas as mulheres realizem o exame preventivo, que suplantem o mal-estar e o desconforto que ele possa causar.

A construção do vivido para as mulheres, acerca do exame de prevenção do câncer cérvico-uterino, não é também, um processo estático. A cada exame, novas impressões vão sendo sedimentadas na sua existência. Nesse momento, a mulher interioriza novas sensações sobre aquela experiência.

Sendo assim, acredito que, a cada reencontro com o profissional de saúde, abremse novas possibilidades para a mulher (re)significar a experiência de se submeter ao exame colpocitológico, nos fazendo refletir
O exame colpocitológico sob a ótica da mulher que o vivencia 
sobre a importância da valorização dos sentimentos aflorados nesse encontro intersubjetivo entre profissional e cliente durante o atendimento.

\section{Enfrentando o exame colpocitológico: manifestações do existir}

Nesta categoria, apreendo que os sentimentos, as percepções que as mulheres trazem consigo à respeito do exame colpocitológico, podem ser frutos das relações humanas, das opiniões de outros sujeitos à respeito do assunto, como também, podem ser oriundos da experiência pessoal de cada mulher, remanescente de situações anteriores ao momento do exame. Seja qual for a origem, a fonte geradora desses sentimentos, posso perceber que eles interferem diretamente no comportamento das mulheres durante o exame, seja de forma positiva ou não.

Os sujeitos relatam que se submeter ao exame colpocitológico é sentir vergonha, medo, nervosismo, constrangimento, ansiedade, dor, alívio e tranqüilidade. Estes sentimentos são vividos e externados por cada mulher de forma ímpar, conforme sua visão de mundo. À sua maneira, colocam o que isso significou para elas:

... o exame ginecológico [...] é muito íntimo, então eu acho muito constrangedor [...] eu suava, molhava a camisola toda, de tão nervosa que eu ficava...

Os sentimentos de constrangimento e vergonha são expressos, ainda, no que se refere à posição e ao toque ginecológico. A sensação de impotência, de desproteção e a perda do domínio sobre o próprio corpo que a posição ginecológica induz, parecem influenciar nesses sentimentos.

... eu me sinto desprotegida [...] esse negócio de por a mão, e por as pernas daquele jeito [...] eu fico super nervosa, quando vou fazer esse tipo de exame. [...] eu odeio ter que abrir as pernas daquele modo.

Aliado a todo este contexto está a "invasão" sofrida pelo corpo da mulher, seja por meio do instrumental médico-hospitalar, seja pelo toque ginecológico. A introdução do espéculo, a utilização do foco luminoso e mesmo o toque manual, embora sejam reconhecidos pelas mulheres como importantes e necessários para a realização do exame, são apontados como situações de incômodo e nervosismo mediante a exposição do corpo:

... esses negócios, tipo aparelho enfiando dentro da gente [...] me incomoda muito, muito mesmo [...] é como se, quando colocam aquela luzinha, tivessem vendo tudo, tudo que tá dentro de mim [...] é uma sensação de estar sendo explorada por dentro..

Exposto, impotente, "imobilizado" e sujeitado à situação, o corpo da mulher é afetado em seu existir e se mostra como vivencia esse momento, por meio de reações, de emoções, de sentimentos quase sempre não percebidos pelos profissionais de saúde.

Durante o exame, comportamentos influenciados por reminiscências do passado puderam ser observados em algumas delas. As mulheres carregam consigo recordações de atendimentos anteriores, quando durante a consulta, a interação, a empatia entre profissional e cliente não aconteceu:

... a mulher já entra fragilizada, e ao mesmo tempo ela quer saber, ela fica curiosa, porque tá mexendo no teu corpo e você tem o direito de saber. $E$ quando a pessoa não te responde, isso te causa [...] ira, constrangimento, aí você não quer retornar.[...] A pessoa que me tratou fo grossa [...]. Eu acho que nós, mulheres, merecemos atenção, respeito e sensibilidade [...] se não tiver sensibilidade, você não tem como captar o que ela tá sentindo [...] ela vai sair e não vai te dizer absolutamente nada, vai sair curiosa por respostas, e não vão tê-las.

No momento do exame, intimidades, segredos, até então resguardados, ficam à mercê do olhar perscrutador do profissional, causando insegurança e medo nas mulheres; e a forma como o profissional de saúde irá lidar com isso parece ser crucial para que se estabeleça uma relação de empatia plena. Assim, é nesse movimento de mostrar-se e esconder-se que os sujeitos - mulher e profissional de saúde - descobrem mais sobre si mesmos, através daquilo que vêem e percebem um no outro.

\section{Interagindo com o profissional de saúde durante o exame: as interfaces da assistência}

Esta categoria abrange os aspectos do exame colpocitológico no que tange às rela- 
ções interpessoais entre profisssionais de saúde e cliente, mostrando as interfaces da assistência.

Em seus discursos, observo que as mulheres consideram como essencial a convivência com o profissional durante o exame colpocitológico, e levam isso em consideração no momento da escolha do serviço de saúde que irá atendê-las.

$\mathrm{O}$ encontro intersubjetivo entre a mulher e o profissional de saúde acontece em maior ou menor intensidade, de acordo, principalmente, com a visão-de-mundo que este traz consigo e incrementa em suas práticas assistenciais.

Pude perceber, à partir dos discursos dos sujeitos, que o atendimento realizado pela enfermeira difere dos demais profissionais de uma forma positiva, e as mulheres demonstram, verbalizam essa diferença em diversos momentos de seus depoimentos.

Alarcón ${ }^{(8)}$ e Yongert ${ }^{(9)}$ pactuam com a idéia de que as enfermeiras desenvolvem um saber que é diferente daquele do médico. As enfermeiras não simplesmente detêm o conhecimento, mas são capazes de disponibilizá-lo a serviço da pessoa e oferecer cuidados de enfermagem com qualidade não só científica, mas, sobretudo, humana. Elas permitem que se instale uma situação de empatia, verdadeira responsável pelo esclarecimento (bilateral) de significados, que caracterizam a forma diferenciada da enfermeira colocar-se junto ao outro:

\begin{abstract}
... fui melhor, hoje eu nem senti [...] a mão da menina (a enfermeira) também é levinha [...] Não sei nem se é a mão, tá? Talvez nem seja [...] principalmente com ela conversando, me deixou mais tranqüila. Eu achei ela muito legal [...] me atendeu muito bem.
\end{abstract}

Pude observar que a consulta de enfermagem é vista pelas mulheres como um espaço para que as mesmas possam ex-istir, numa relação onde o sentimento é de igualdade entre as partes - cliente e enfermeira - proporcionando às mulheres mais confiança em si mesmas:

... uma conhece a outra: você, enfermeira, consegue perceber, quando o paciente entra, se ele tá agitado, se tá nervoso [...] por ter sensibilidade, ser o profissional que tá preparado pra isso [...] Vai ser uma coisa muito melhor feita, com muito mais atenção, com muito mais carinho, muito mais respeito.
Este sujeito fala de um conhecimento mútuo, que vai além da razão, que se mostra como inteligência que intui, como sensibilidade. Orientação, respeito, cumplicidade, sensibilidade foram, da mesma forma, mencionados como um diferencial do atendimento realizado pela enfermeira, como exemplifica a fala seguinte:

Hoje, fazer o exame foi melhor, muito meIhor [...] porque o exame foi feito por uma enfermeira doutora [...] está sendo meIhor do que com o doutor [...] foi uma coisa assim, mais respeitosa...

Ao assumir uma postura reflexiva, as mulheres, de submissas, passam a se mostrar como seres existentes: exigem respeito, escuta e diálogo. Saem do anonimato e conquistam espaços no contexto assistencial feminino, até então, ditado por normas e rotinas inflexíveis que precisam ser repensadas, já que caminhamos para a humanização da assistência nos diversos segmentos de atenção à saúde.

Mediante essas reflexões, não é mais possível cegar-se ao fato de que o corpo é apenas um elemento do sujeito e de seu mundo, uma das inúmeras possibilidades dessa existência como ser ${ }^{(10)}$.

Assim, acredito na abordagem diferenciada adotada pela enfermeira, quando inscrita na perspectiva de desenvolver na mulher a propriedade de seu corpo, que só a ela pertence. Ela própria pode compreendê-lo e reconhecer nele suas alterações e necessidades, uma vez que não se pode compreender o gesto do outro, a não ser pela comunicação existente entre mim e ele, e esta se baseia nos significados comuns, presentes no vivido de cada um, evidenciando-se assim, que é na corporeidade que se compreende o outro e se percebem as coisas ${ }^{(11)}$.

Nesta categoria também fica evidente o descontentamento das mulheres com o atendimento oferecido pelo profissional médico, reflexo do modelo biomédico, de cunho curativo, centrado na recuperação do corpo físico. Ver o corpo dessa forma fragmentada é cegar-se e ensurdecer-se à subjetividade e aos sentimentos que emanam do ser e o engendram. É centrar-se simplesmente na técnica e esquecer-se que ali vibra um corpo existente, vivo, que espera e implora do outro uma relação mais humana, autêntica, no sentido do todo. A inautenticidade da relação
O exame colpocitológico sob a ótica da mulher que o vivencia 
médico-cliente faz calar o corpo da mulher e intimidar o seu ser, fazendo com se coloque numa posição de subserviência, subjugamento e submissão.

Embora haja a valorização desse profissional e incontestável apoio ao seu saber, as mulheres queixam-se da forma do atendimento adotada pelo médico e do vínculo (ou ausência dele) estabelecido entre ambos durante $o$ atendimento.

No encontro entre médico e cliente, a atitude do médico está centrada sobre a autoridade profissional. Ele é um técnico e normalmente não vai além disso. Ele vê a doença apenas como um caso que precisa ser resolvido pela sua competência. O cliente é um objeto que ele disseca, analisa, diagnostica e em torno do qual se faz a prescrição, avaliando, posteriormente, os resultados.

... todas as vezes que eu consultei sempre foi muito chata a consulta, aquela consulta muito fria.

... o médico parece que é uma coisa mais [...] de obrigação do que tá fazendo [...] é só mais um paciente, vai lá, faz o exame e acabou.

Os médicos, ao optarem pela abordagem biomédica, limitam-se às manifestações clínicas, desprezando a subjetividade das mulheres, não permitindo que se estabeleça entre eles uma relação empática, subsidiada pela valorização do indivíduo como ser integral.

Porém, oferecendo oportunidades para a mulher falar de si mesma, ela poderá ser melhor compreendida, não só pelo profissional que a atende, mas por si mesma, uma vez que, a cada nova oportunidade de refletir sobre suas experiências, ela passa a ter uma consciência mais clara do que está acontecendo consigo mesma; apropria-se do seu pensar e de seu agir, abrindo possibilidades para (re)significar seu mundo-vida, uma vez que o vivido do sujeito constitui uma força dinâmica, que age poderosamente no indivíduo e da qual depende, em termos gerais, tudo que nele acontece ${ }^{(10)}$.

Ao voltarmos nosso olhar para a mulher, contemplando-a em sua totalidade, estaremos oferecendo condições para que a consulta passe a se configurar como um encontro de subjetividades, onde certamente estarão presentes a atenção, o respeito e a sensibilidade mútuos.
Assim, acredito, como Capalbo ${ }^{(12)}$, que a doença é uma facticidade não só do corpo, mas de todo o ser humano enquanto ser-nomundo. Por isso, não se pode aceitar que o profissional de saúde busque "tratar doenças" e não o "indivíduo doente" no contexto de sua vida como ela é vivida, ou seja, em sua facticidade. $\mathrm{O}$ homem que adoece não está isolado, vivendo sem os outros. Os outros são sempre co-presentes em todas as nossas vivências.

Fica explicitada, através dos depoimentos das mulheres, que há uma iminente necessidade de reflexão dos diversos segmentos do setor saúde para que ocorram profundas mudanças na postura dos profissionais, principalmente do médico, no que diz respeito à concepção do que realmente valorizar ou não, durante um atendimento.

É necessário salientar que, embora o modelo assistencial biomédico ainda seja hegemônico, observa-se que há um movimento que esboça interesse em romper com esse paradigma curativo, sobretudo no $\mathrm{HC} /$ UFMG.

Essa busca por uma abordagem alternativa ao modelo vigente desperta, no íntimo de cada sujeito, a consciência de que é importante despir-se da "armadura tecnológica" à qual permanecemos envoltos durante tanto tempo, para ir ao encontro das coisas como elas realmente são. É necessário compreender que é o outro, e não eu, quem define suas metas de vida e determina os meios mais apropriados para alcançá-las, o que não impede que eu ofereça sugestões oportunas, que estejam sintonizadas com aquilo que o sujeito expressou no diálogo e com o que ele pensa e sente.

É preciso entender que os profissionais de saúde, para transitarem da abordagem de atendimento ao corpo doente para a busca da compreensão do outro em sua totalidade, necessitam de muita determinação, pois optar por essa trajetória significa ir de encontro a muitos princípios e conceitos incorporados, impregnados, calcificados pelo tempo.

Os discursos das mulheres revelam que o HC/UFMG possui um atendimento que é diferenciado de outras instituições de saúde. Acredito que essa forma de atendimento peculiar ao HC/UFMG não advém de uma causa única. Pelo contrário, penso que é a miscigenação de saberes e formas de pensar, a forte 
influência acadêmica - característica de um hospital universitário - que torna isso possível. A presença de outros profissionais da área da saúde que não médicos e enfermeiros, favorece a formação de equipes multiprofissionais e interdisciplinares, propiciando o compartilhamento do poder e das decisões, ou pelo menos, faz com estas sejam discutidas, desmistificando a figura de onipotência médica, além de favorecer uma "fuga" do modelo assistencial biomédico pelas diferentes formas que os diferentes profissionais têm de pensar e agir.

Além do mais, o espaço que é dado à enfermeira no HC/UFMG, sobretudo no setor ambulatorial, a torna uma profissional de referência para os usuários e demais profissionais dos diversos programas assistenciais. Sendo assim, a abordagem diferenciada que a enfermeira adota acaba repercutindo, também, nos demais profissionais atuantes nos programas assistenciais, fruto dessa convivência multiprofissional e interdisciplinar.

É possível perceber que há um vínculo muito especial estabelecido entre as mulheres e o HC/UFMG, alicerçado em valores que extrapolam a capacidade técnica dos profissionais que ali trabalham. Em nome desse vínculo, elas suplantam várias adversidades para conseguirem uma consulta, apesar de saberem que poderiam ser atendidas muito mais facilmente em outras instituições de saúde:

... eu poderia tá lá no posto, perto da minha casa, marcando uma consulta com um médico que tem lá, com uma médica que tem lá, e eu não quis.

O hospital mostra-se como um local onde elas encontram não apenas atendimento, mas também compreensão, abertura para o diálogo. As mulheres relatam existir uma ligação entre elas e os profissionais, que extrapola os vínculos exigidos pela terapêutica, laços aos quais elas conferem um imenso valor:

\footnotetext{
... aqui o acompanhamento também é meIhor [...] porque eu tenho a possibilidade de sentar, conversar, coisa que é tão difícil! [...] Quando eu me sinto à vontade, num determinado lugar, eu prefiro continuar ali sempre, porque eu acho isso muito importante.
}

No entanto, não ousaria dizer, nesse momento, que o HC/UFMG rompeu com o modelo assistencial hegemônico e que já foi es- tabelecido um novo paradigma, nesse sentido, mas acredito que há um movimento, ainda incipiente, tímido, que busca essa ruptura, embora toda a história deste hospital tenha sido construída sobre os alicerces do modelo biomédico.

Para que se dê essa mudança, penso que é necessário que esse movimento se desperte, primeiramente, em cada um de nós, como partes que somos dessa instituição e que fazem o HC ser como é.

No entanto, é preciso despertar os responsáveis pelas políticas institucionais para a necessidade de transformar o modelo de saúde hegemônico, para que assim, com a confluência de idéias entre instituição e instituídos, possamos buscar caminhos alternativos que nos levem, de forma harmônica, ao objetivo comum de todos nós: um atendimento à saúde que seja eficiente mas, sobretudo, que não ignore a individualidade e a dignidade de cada sujeito como ser.

\section{ALGUMAS CONSIDERAÇÕES}

Este trabalho possibilitou-me compreender que a mulher, ao vivenciar o exame colpocitológico, não é apenas um colo uterino a ser explorado, mas um corpo que tem sentimentos, que pulsa e vibra, que interage com o mundo, com o outro e consigo mesmo; que deixa transparecer por gestos, expressões, olhares, palavras e silêncio, como experiencia esse momento.

A mulher, ao buscar o atendimento nos serviços de saúde, está aberta ao mundo da assistência, onde o cuidar da saúde não acontece como possibilidade única e isolada, mas sim no projetar-se para ser mulher, companheira, filha, trabalhadora, dentre outras.

Na busca pela saúde, as mulheres são capazes de superar muitas adversidades, nos fazendo refletir sobre a importância de repensarmos nossa postura como profissionais de saúde. Acredito que cabe a nós fazermos dessa experiência das vidas das mulheres um momento menos doloroso, passando a consulta a configurar-se como um espaço para a mulher ser examinada, sem necessariamente, deixar de ser ouvida, respeitada e protegida. Acredito, ainda, que isso será possível somente através de uma relação de real empatia entre cliente e profissional de saúde, onde
O exame colpocitológico sob a ótica da mulher que o vivencia 
Aline Fernandes de Paula Anézia Moreira Faria Madeira um abre espaço para o outro existir, experimentar, compartilhar sentimentos e sensações, na (re)construção de seus significados, utilizando sim o aparato tecnológico, mas mantendo sempre, como ponto central do atendimento, o encontro com o outro. Ao reconhecer que, em cada consulta, novas possibilidades surgem para profissional e cliente (re)criarem opiniões e conceitos, surgirão novos pontos de vista, perspectivas mais positivas com relação ao exame colpocitológico, que certamente serão incorporados no vivido de cada um.

Felizmente, a reação rumo à mudança vem sendo formulada concretamente pelo conjunto de pessoas que ensaiam práticas significativas em todos os lugares e em todas as situações do mundo atual. Muitos são os sujeitos dessas mudanças; elas se orientam por um novo sentido de viver e de atuar, por uma nova percepção da realidade e por uma nova experiência do ser, emergem do caminho coletivo que se fez caminhado.

Trata-se, na verdade, de uma compreensão existencial que só pode ser obtida pela reflexão que a mulher faz sobre a sua experiência de submeter-se ao exame colpoci-tológico. Assim, o trabalho fundamental do profissional de saúde, na ação terapêutica-educativa, é de ajudar a mulher a se compreender como sujeito, que atribui significados ao seu corpo, à sua vida, ao seu destino e ao seu relacionamento com o outro e com o mundo. Essa apreensão sobre si mesma não vem, propriamente, da força do raciocínio, mas por uma elucidação, uma descoberta interior, que esclarece não apenas a inteligência mas também a emoção, fazendo com que a mulher tenha uma nova maneira de pensar e de sentir, que dá um novo sentido à sua vida, à sua existência.

Ao percorrer essa trajetória, amparada pela fenomenologia, acredito que não caminho para o limite. Pelo contrário, sei que novas trilhas sempre se abrirão, convidandonos à novas incursões. Frente ao caráter de inesgotabilidade do fenômeno, instigo e convido a novos desafios no campo da investigação científica, buscando uma compreensão maior do que significa para a mulher ser submetida ao exame colpocitológico.

\section{REFERÊNCIAS}

(1) Ministério da Saúde. Instituto Nacional do Câncer. Controle do câncer: uma proposta de integração ensino-serviço. $3^{\mathrm{a}}$ ed. Rio de Janeiro; 1999.

(2) Formiga Filho JFN. Políticas de saúde reprodutiva no Brasil: uma análise do PAISM. In: Galvão L, Diaz J. Saúde sexual e reprodutiva no Brasil. São Paulo: Hucitec; 1999. p.151-63.

(3) Ministério da Saúde. Instituto Nacional do Câncer. Programa nacional de controle do câncer do colo uterino. Brasília; 2000.

(4) Silveira GPG, Pessini SA. Câncer de colo uterino: lesões precursoras. In: Halbe HW. Tratado de ginecologia. $2^{\mathrm{a}}$ ed. São Paulo: Roca 1993. cap.172, p.1788-806.
(5) Ferreira MLS, Andrade PFL, Costa ES. Prevenção e detecção precoce do câncer de colo uterino. UNESP [periódico online] 2001; 31(5). Disponível em: <http://www. connectmed.com.br/printervision. php3? content_id=74141\&logged=Y $>$. [23 abr. 2001]

(6) Martins J, Bicudo MAV. Pesquisa qualitativa em psicologia: fundamentos e recursos básicos. São Paulo: Moraes; 1989.
(7) Alarcón NG. Ética em el cuidado de enfermeria. In: Herrara BS, Afanador NP, organizadores. Dimensiones del cuidado. Bogotá: Grupo de cuidado. Faculdad de Enfermeria - Universidad Nacional de Colômbia, 1997. p.77-82.

(8) Yongert I. Enfermagem na Bélgica. In: Anais do $41^{\circ}$ Congresso Brasileiro de Enfermagem; 1989 set 2-7; Florianópolis. Florianópolis: ABEnSanta Catarina; 1989. p.133-44.

(9) Merleau-Ponty M. Fenomenologia da percepção. São Paulo: Martins Fontes; 1999.

(10) Gomes ML. Quando são mulheres (clientes e enfermeira) na consulta de enfermagem. Rev Enferm UERJ 1996; (edição extra): 109-12.

(11) Capalbo C. A fenomenologia a partir de Edmund Husserl e sua repercussão na área da saúde. Rev Enferm UERJ 1998; 6:415-9. 